\title{
Long-term reduction of nitrogen fertilizer use through knowledge training in rice production in China
}

\author{
Jikun Huang a,*, Zhurong Huang a , Xiangping Jia a , Ruifa Hu ${ }^{\text {b }}$, Cheng Xiang a \\ a Center for Chinese Agricultural Policy, Chinese Academy of Sciences and Institute for Geographical Sciences and Natural Resources Research, Beijing, China \\ b School of Management and Economics, Beijing Institute of Technology, Beijing, China
}

\section{A R T I C L E I N F O}

\section{Article history:}

Received 4 May 2014

Received in revised form 23 December

2014

Accepted 6 January 2015

Available online 27 January 2015

\section{Keywords:}

Nitrogen fertilizer

SSNM

Knowledge training

Extension

Farmers

\begin{abstract}
A B S T R A C T
Nitrogen $(\mathrm{N})$ fertilizer has been excessively used in China's crop production, resulting in nonpoint pollution and significant greenhouse gas emissions. Previous studies show that farmers can reduce $\mathrm{N}$-fertilizer upon receiving knowledge training. However, there is little evidence of the effectiveness of this effort in the long term. Based on an experimental study of site-specific nutrient management for rice production in China and a unique household dataset captured over seven years, this study shows that the traditional training approach has not been effective in reducing Chinese farmers' N-fertilizer use. Persistently reducing farmers' excessive use of $\mathrm{N}$-fertilizer in the long term will require intensive in-field guidance something that requires substantial investment and institutional innovation.
\end{abstract}

(c) 2015 Elsevier Ltd. All rights reserved.

\section{Introduction}

Fertilizer has played an important role in China's crop production, but it has been excessively used for decades. According to Heisey and Norton (2007), China's fertilizer application per hectare (ha) in crop production grew rapidly after the 1960s, and in 1980 surpassed the average level of fertilizer application of industrialized countries. By 2000, China's average fertilizer application measured in element nutrients exceeded $200 \mathrm{~kg} / \mathrm{ha}$ - a figure much higher than the average application in India (less than $100 \mathrm{~kg} / \mathrm{ha}$ ) and in industrialized countries (about $120 \mathrm{~kg} / \mathrm{ha}$ ). In 2006, China consumed 31 million tons of chemical nitrogen (N) fertilizer, accounting for about 32 percent of global N consumption (Heffer, 2009). Several studies have shown that in China, $\mathrm{N}$-fertilizer use has been excessively used in grain production (Cai et al., 2002; Chen et al., 2006; Cui et al., 2008; Fan et al., 2007; Ma et al., 2008; Peng et al., 2002; Yan et al., 2012) and vegetable farming (Chen et al., 2004; He et al., 2009).

The excessive use of $\mathrm{N}$-fertilizer has led to severe environmental problems and significant greenhouse gas (GHG) emissions. For example, the high rate of $\mathrm{N}$-fertilizer use in China has led to large $\mathrm{N}$ losses in the form of ammonia volatilization and $\mathrm{N}$ leaching into groundwater and lakes (Zhu and Chen, 2002), as well as soil acidification, which could result in declines in agricultural productivity

\footnotetext{
* Corresponding author. Tel.: +86106488 9833; fax: +861064856533

E-mail address: jkhuang.ccap@igsnrr.ac.cn (J. Huang).
}

(Guo et al., 2010). Moreover, it has been estimated that agriculture and agrochemical industries account for at least 15 percent of China's total fossil energy use and nearly 20 percent of its total GHG emissions (SAIN, 2010). Emissions from N-fertilizer production, transportation, and application alone accounted for nearly 30 percent of GHG emissions in agriculture in 2007 - equivalent to 5 percent of China's total GHG emissions (SAIN, 2010). Thus, improved N management is of great importance to protecting the environment, creating sustainable agricultural production, and mitigating climate change in China.

The reasons for China's high rate of $\mathrm{N}$-fertilizer use in agriculture have been debated; most tend to agree that farmers' lack of knowledge on efficient $\mathrm{N}$-fertilizer use is a primary cause. For example, Huang et al. (2008, p. 165A) argue that "farmers [there] just do not know that they are overusing fertilizer. Many farmers in China learned to use chemical fertilizers when $\mathrm{N}$-responsive varieties first came onto the market in the early years of the Green Revolution [during 1960-1980]. Since then, new varieties that are more responsive to chemical fertilizer applications have become more widely available and used in China." Chinese farmers have relied on their previous experience, which has told them that the use of more fertilizer leads to higher crop yields (Huang et al., 2008). Meanwhile, the poor performance of the public extension system has also constrained farmers' access to new knowledge of efficient fertilizer use, particularly as extension agents are largely engaged in commercial activities - including the sale of fertilizer - to balance their budget deficits (Hu et al., 2009). In addition, politically, ensuring food security through increased fertilizer use in 
crop production has been one of China's major achievements, giving the government pause in reducing $\mathrm{N}$-fertilizer use, despite emerging evidence of its adverse environmental consequences (SAIN, 2010). Consequently, improving $\mathrm{N}$-fertilizer use efficiency by reducing its excessive use has never been a mainstream or central task among public extension agents. Another contributor to the high rate of $\mathrm{N}$-fertilizer use in China has been fertilizer subsidies. However, Huang et al. (2011) show that those subsidies are nondistorting, because they are not coupled with farmers' purchases of fertilizer.

A number of recent empirical studies have verified the effectiveness of knowledge training (of various approaches) on improving the efficiency of $\mathrm{N}$-fertilizer application in China's agricultural production (IRRI, 2012; Hu et al., 2007; Huang et al., 2008, 2012; Jia et al., 2013; Peng et al., 2006; Xiang, 2012). For example, some studies show that, compared to a control group of farmers, farmers who partook in participatory training on the appropriate use of $\mathrm{N}$-fertilizer saw their $\mathrm{N}$-fertilizer use decrease by about $15-20$ percent in rice production (Hu et al., 2007; Huang et al., 2008). Through more intensive in-field training and in-season guidance, farmers could reduce $\mathrm{N}$-fertilizer use by more than 30 percent and increase rice yield by 5 percent. Similar short-term effects were also found in maize and wheat studies. For example, Huang et al. (2012) found that by partaking in a 1-2-hour training program on nutrient management, farmers in the North China Plain reduced $\mathrm{N}$ use by 22 percent in maize production. Following the same approach, Xiang (2012) found that knowledge training on improving $\mathrm{N}$ management could reduce $\mathrm{N}$-fertilizer use in wheat production, although the rate of reduction was lower than that in maize production.

Nevertheless, nearly all these findings vis-à-vis knowledge training and reductions in farmers' $\mathrm{N}$-fertilizer use were based on evidence gathered immediately following the knowledge training or interventions. It is not clear whether the effectiveness of various training programs can be retained in the long term. It could be argued that the farmers who participated in the experiments might have felt embarrassed about disregarding the researchers' advice; likewise, when the training was finished, they might have renewed their previous $\mathrm{N}$-fertilizer application practices, thinking that the persistent reduction of $\mathrm{N}$-fertilizer use in the long term could reduce the total $\mathrm{N}$ supply in the soil and adversely affect crop yield. In such cases, they might renew the use of conventional practices by using even more $\mathrm{N}$-fertilizer in the long term. As a result, questions arise regarding whether different training approaches are sufficient in introducing fertilizer-saving technologies to smallholder farmers, and whether the reduction of $\mathrm{N}$-fertilizer use reduces crop yield in the long term. ${ }^{1}$

The answers to the above questions are of great interest to policymakers, the fertilizer industry, and farmers. The findings of the current study have important policy implications - and not just in terms of nonpoint pollution, GHG emissions, and food security, but also in terms of food consumption and production, and $\mathrm{N}$-fertilizer trade in China. Having an understanding of the longterm effects of various training approaches (e.g., one-time training vs. intensive, in-field guidance training) may thus help in designing future extension programs that encourage farmers to adopt sustainable-agriculture technologies, in China and in other developing countries.

The overall goal of this study is to examine the long-term effects of farmers' knowledge training on improved $\mathrm{N}$ management with

\footnotetext{
1 It is known that crop yield is related to crop $\mathrm{N}$ uptake which depends on $\mathrm{N}$ available in the soil and by fertilizers. Therefore, when knowing the $\mathrm{N}$ available in the soil, the required $\mathrm{N}$ fertilizer can be calculated for maintaining the yield. A number of field experiments has shown that the conventional practice in rice production in China overused $\mathrm{N}$ fertilizer and the moderate reduction of $\mathrm{N}$ fertilizer use would not adversely affect crop yield (IRRI, 2012; Peng et al., 2006).
}

respect to rice production in China. Specifically, it compares the effectiveness of different knowledge training approaches on longterm $\mathrm{N}$-fertilizer use, and examines whether reductions in $\mathrm{N}$-fertilizer use have resulted in diminished rice yields.

The remainder of this paper is organized as follows. Section 2 discusses the study's research design and data collection methods. Section 3 provides descriptive analyses of $\mathrm{N}$-fertilizer use among farmers participating in various training approaches. Section 4 examines the impact of these training approaches on farmers' use of $\mathrm{N}$-fertilizer, by using multivariate analysis. The final section concludes by discussing policy implications.

\section{Research design and data}

\subsection{Experimental trials of training approaches}

The technology addressed by this study and which was introduced to farmers through knowledge training is the site-specific nutrient management (SSNM) for rice production in China; it is a technology that was developed by the International Rice Research Institute (IRRI) and its collaborators in China in the early 2000s (IRRI, 2012; Peng et al., 2006; Wang et al., 2001). In essence, SSNM is a technology based on the site-specific conditions of rice production; it enables farmers to tailor nutrient management to the specific conditions of their own fields and improve efficiency or achieve reductions (in the case of excessive use) of $\mathrm{N}$-fertilizer use without affecting rice yield (Buresh, 2009). However, farmers usually modify SSNM technology to fit their own demographic characteristics (Byerlee and de Polanco, 1986). Regarding N management, Khanna (2001) found that farmers adopted SSNM technologies sequentially and only partially. More recent empirical evidence from China shows that after farmers in Shandong attended a knowledge training seminar on improved $\mathrm{N}$ management, they followed the recommendation of reducing overall fertilizer use in maize production (Jia et al., 2013). Nevertheless, the recommendation of balanced $\mathrm{N}$ use - namely, reducing $\mathrm{N}$-fertilizer use in the early vegetative season and increasing $\mathrm{N}$-fertilizer use at later stages - was not followed due to the related increase in labor demand. Sitespecific technologies, once put into practice, were always modified and adapted by farmers.

To examine the impacts of SSNM technology as distributed through various training approaches, the research team conducted field experiments in rice production in the selected villages over the 2003-2005 period (details of the sampling approach are discussed in the next subsection). The fieldwork was run by a team comprising economists, agronomists, and soil scientists, along with extension staff from local township extension stations. First, the research team randomly sent out flyers to a group of farmers (about 20-30 farmers) in each village and invited them to take part in a participatory knowledge training workshop on SSNM technology within a few days. Most of them accepted the invitation and came to the workshop; only a few were not available and did not join the workshop. During the workshop, farmers were asked to discuss soil conditions and their fertilizer-application practices for rice production; those practices included application timing, and the types and amounts of various fertilizers used during the entire rice growing season. Based on these discussions, the agronomists and soil scientists of this project team, together with the farmers, explored an appropriate package of SSNM technology that was then recommended to the village farmers. As the aim of distributing this technology was to reduce $\mathrm{N}$-fertilizer use without lowering rice yield, and was introduced by scientists, there was no resistance from the participating farmers. Second, within this group of farmers, we invited about 10 farmers (ranging from eight to 12 among the villages studied) to experiment with the SSNM technology in their own rice fields. We divided these farmers into two groups (as shown in 


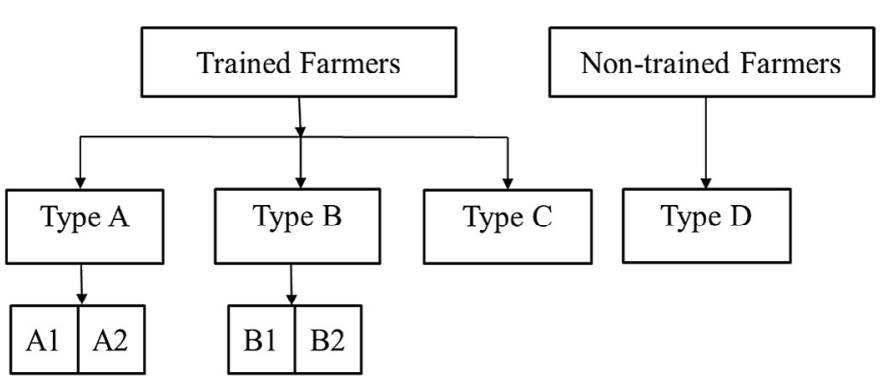

Fig. 1. Experimental design of participatory training for SSNM technology.

Fig. 1): Type A (two to three farmers) and Type B (the other six to nine farmers) group farmers. The Type A farmers were intensively guided by the local extension staff and were asked to follow the recommended SSNM technology as closely as possible in the coming rice production season. Type $B$ farmers were also asked to experiment with the SSNM technology, but the extension staff members were available only upon request during the rice growing season. Type B farmers thus received much less in-field guidance in SSNM technology application than did for Type A farmers. The remaining trained farmers (Type C) planted rice without further intervention, following the training workshop. Dividing the trained farmers into three groups in this manner reflects various levels of extension effort. To construct a control group for comparison, we randomly selected five rice farmers who did not participate in the village training workshop on SSNM (nontrained; Type D farmers).

To implement the experiment, we asked Type A and Type B farmers to conduct their respective trials in their largest rice plots. After the plots were selected, each plot was divided by a levee into two equally sized subplots (A1 and A2 for Type A farmers; B1 and B2 for Type B farmers). The levee was covered with plastic film to prevent nutrient migration between the two subplots. On subplots A1 and B1, the farmers applied the SSNM technology; on subplots $\mathrm{A} 2$ and $\mathrm{B} 2$, the farmers followed their own conventional practices.

\subsection{Study sides and data collection}

Data used in this study are from two rounds of surveys in the provinces of Guangdong and Jiangsu. ${ }^{2}$ For the first round, in Guangdong, the participatory knowledge training workshops (hereafter, the "training workshop") were conducted in three villages in 2003 and two villages in 2004. In Jiangsu, the same training workshops were conducted in two villages in 2004 and 2005. (For ease of reference, in the remainder of this paper, we use "2004" or "20032005" in reference to 2003-2004 in Guangdong and 2004-2005 in Jiangsu.) A set of questionnaire-based household surveys were conducted for all farmers (i.e., Type A, B, C, and D farmers). Data collected and used in this study include that pertaining to fertilizer use and rice yield at the plot level, and the basic characteristics of household (e.g., family size and cultivated land) and individuals (e.g., gender, age, education, marriage of each family member).

The second-round survey was conducted at the end of 2010. In this survey wave, we returned to the nine villages to conduct a follow-up survey of the same households in Guangdong (five villages) and Jiangsu (four villages) that had attended the training workshops in 2003-2005. To the greatest extent possible, our strategy in the second round was to ask the same respondents the same questions, as well as a few new questions specific to $\mathrm{N}$ use. As the Type $A$ and Type $B$ farmers had removed the levee and did not dif-

\footnotetext{
2 See footnote 1 .
}

ferentiate $\mathrm{N}$-fertilizer use between the subplots (i.e., the previous $\mathrm{A} 1$ and $\mathrm{A} 2$, or $\mathrm{B} 1$ and $\mathrm{B} 2$ ) beyond the first-year trial, in the followup survey in 2010, we surveyed Plot A (i.e., the merged plot comprising subplots $A 1$ and $A 2$ ) and Plot $B$ (i.e., the merged comprising subplots B1 and B2) of rice production for the Type A and Type B farmers, respectively.

Data on the samples and the related plots are presented in Appendix Table A1. Among the samples in 2004, there were 25 Type A farmers and 124 Type B farmers (column 1); for the 2010 followup survey, most of the Type A and Type B farmers were located (22 and 99, respectively; column 2 ). The attrition rate was similarly low (70 percent; 38 of 54 farmers) for Type C farmers, who had received training but no guidance. Attrition was somewhat higher for the control group: we were able to locate roughly half of them (21 of 41 farmers; column 5). Attrition occurred mainly for the following two reasons. First, during the 2004 and 2010 time periods, some land was converted to nonfarm use, or some farmers rented their land to other farmers. Second, a few farmers had migrated in recent years to urban areas, for off-farm employment. In summary, the full dataset includes 244 farmers in 2004, of which 180 farmers and their plots were located in 2010 (Appendix Table A1).

\section{3. $\mathrm{N}$-fertilizer use and knowledge training}

Knowledge training in 2004 effectively reduced farmers' $\mathrm{N}$ use in the sample villages. As shown in Table $1, \mathrm{~N}$-fertilizer use on Type A1 plots was $146 \mathrm{~kg} / \mathrm{ha}$ - a figure significantly smaller than that of Type D farmers ( $228 \mathrm{~kg} / \mathrm{ha}$ ). The amount of $\mathrm{N}$ use on Type B1 plots (159 kg/ha) was also significantly lower than that of Type C farmers. The traditional training (delivery of a one-hour course) also reduced farmers' use of N-fertilizer in rice production in 2004 (Type C: $197 \mathrm{~kg} /$ ha), though not statistically significantly so. Meanwhile, N-fertilizer use on the A2 plots (198 kg/ha) and B2 plots (193 kg/ha) were also slightly lower than that of Type D farmers (228 kg/ha), implying that farmers might apply the SSNM practice on nonexperimental plots after receiving knowledge training.

Six years after the training, the rate of $\mathrm{N}$-fertilizer use in rice production in the study area increased significantly. The average rate of $\mathrm{N}$-fertilizer use by Type $\mathrm{D}$ farmers (control group) increased from 228 to $252 \mathrm{~kg} / \mathrm{ha}$ during that time. Additionally, the average amount of N-fertilizer use by Type A farmers reached $202 \mathrm{~kg} / \mathrm{ha}$ in 2010 a figure even higher than that seen in their conventional practice, six years previous (Type A2: $198 \mathrm{~kg} / \mathrm{ha}$ ). Similarly, the average rate of $\mathrm{N}$-fertilizer use by Type B farmers increased to $209 \mathrm{~kg} / \mathrm{ha}$ in 2010 , which was higher than that seen on the B2 plots in 2004 (conventional practice: $193 \mathrm{~kg} / \mathrm{ha}$ ).

The overall increase in the use of $\mathrm{N}$-fertilizer in the study area seems to relate to changes in the prices of $\mathrm{N}$-fertilizer and rice. As shown in Table 2, in the 2004-2010 period, paddy procurement

Table 1

Nitrogen fertilizer use (kg/ha) in rice production in 2004 and 2010, in Jiangsu and Guangdong, China.

\begin{tabular}{lll}
\hline & 2004 & 2010 \\
\hline $\begin{array}{l}\text { Type A farmers } \\
\text { Plot A1 }\end{array}$ & $146(0.001)^{* * *}$ & $202(0.117)$ \\
Plot A2 & $198(0.258)$ & \\
Type B farmers & $159(0.000)^{* * *}$ & $209(0.069)^{*}$ \\
Plot B1 & $193(0.032)^{* *}$ & \\
Plot B2 & $197(0.183)$ & $252(0.856)$ \\
Type C farmers & 228 & 257 \\
Type D farmers & & \\
\hline
\end{tabular}

${ }^{*},{ }^{* *}$, and ${ }^{* * *}$ denote statistical significance of nitrogen fertilizer use by Type A, B and $C$ farmers comparing to nitrogen fertilizer use by control farmers (Type D) in the same year at the $5 \%, 1 \%$, and $0.1 \%$ levels, respectively. The figures in parentheses are absolute p-ratios of estimates. 
Table 2

Price ratio of nitrogen fertilizer to paddy at farm gate in Jiangsu and Guangdong, China.

\begin{tabular}{clll}
\hline & Average & Jiangsu & Guangdong \\
\hline $2003-2005$ & 2.16 & 2.11 & 2.23 \\
2003 & 1.95 & 1.96 & 1.96 \\
2004 & 2.16 & 2.10 & 2.22 \\
2005 & 2.38 & 2.26 & 2.51 \\
2010 & 1.67 & 1.50 & 1.88 \\
\hline
\end{tabular}

Source: National Development and Reform Commission, Compilation of the Agricultural Production Costs and Returns (2003, 2004, 2005, 2006, and 2011).

prices increased much more than $\mathrm{N}$-fertilizer prices did. On average, the price ratio of $\mathrm{N}$-fertilizer to paddy at farm gate decreased from 2.16 in 2004 to 1.67 in 2010 (i.e., a 23-percent decline). This upwardly trending price ratio acted as an incentive that encouraged the increased use of N-fertilizer in both Jiangsu and Guangdong.

Nevertheless, six years after the initial training experiment, $\mathrm{N}$-fertilizer use by Type A and Type B farmers remained significantly lower than that of the control-group farmers (Type D). As shown in Table 1, N-fertilizer use by Type A farmers ( $202 \mathrm{~kg} / \mathrm{ha}$ ) was significantly lower than that of the nontrained group (Type D: $257 \mathrm{~kg} /$ ha). The average rate of $\mathrm{N}$-fertilizer use by Type $\mathrm{B}$ farmers was $209 \mathrm{~kg} / \mathrm{ha}$, which was also significantly lower than that of the Type $\mathrm{D}$ farmers. It seems that the training effects were retained by those farmers who had conducted their own in-field experiments (Type A and Type B farmers).

In the graphical analysis, the long-term effects are clearer for the Type A and Type B farmers (Fig. 2). The four lines were all upwardly sloping, suggesting an increase in the study area in $\mathrm{N}$ use from 2004 to 2010 . Notwithstanding this uniform increase, the rates of $\mathrm{N}$-fertilizer use on Type A1 and Type B1 were significantly lower than that for traditional training (line $C$ ) and nontraining (line $D$ ). This means that the intensive training had persistent effects in reducing farmer's N-fertilizer use. Interestingly, the traditional approaches to training delivery, despite their having seemingly shortterm effects, could not make a long-term impact, as line $C$ almost converges with line $D$ in 2010.

\section{Multivariate analysis}

Because many factors could simultaneously affect farmers' $\mathrm{N}$-fertilizer use, multivariate analysis is required to identify the magnitude and significance of various training approaches. In this section,

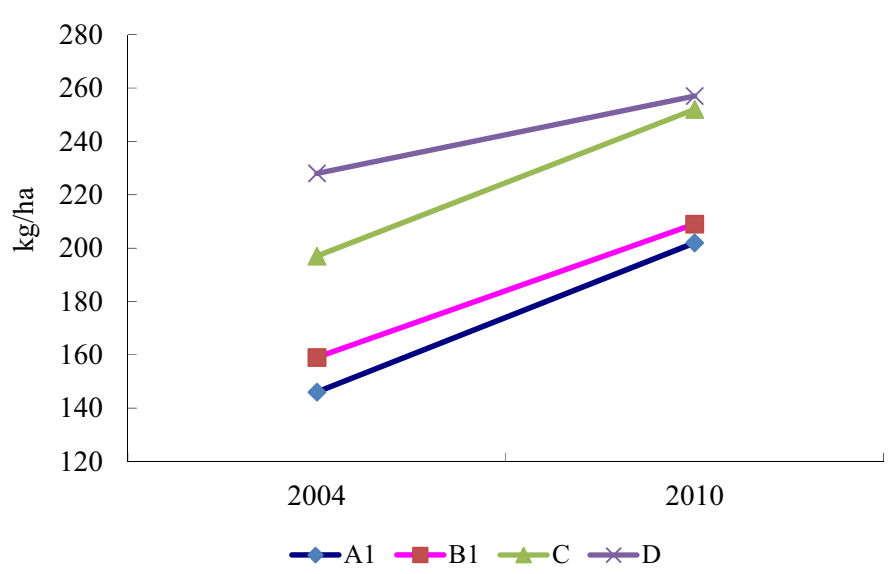

Fig. 2. Nitrogen use in rice production under different training schemes, in China, 2004-2010. we specify a multivariate model that seeks to isolate the impact of training from other factors.

\subsection{The model}

To estimate the long-term impacts of SSNM training on farmers' $\mathrm{N}$-fertilizer use in rice production, we specify the following empirical model:

$$
\begin{aligned}
N_{i j t}= & a_{0}+P_{N t} / P_{R t}+\alpha_{1} A 1_{2004}+\alpha_{1} A 2_{2004}+\alpha_{3} A_{2010}+\beta_{1} B 1_{2004} \\
& +\beta_{1} B 2_{2004}+\beta_{3} B_{2010}+\delta_{1} C_{2004}+\delta_{2} C_{2010}+\omega Z+e_{i}
\end{aligned}
$$

where $N_{i j t}$ is the overall $\mathrm{N}$-fertilizer use per hectare in rice production on the $i^{\text {th }}$ plot of the $j^{\text {th }}$ farmer in time period $t(t=1$ for 2003/ $2004 / 2005$ and $t=2$ for 2010$) . \mathrm{P}_{\mathrm{N}} / \mathrm{P}_{\mathrm{R}}$ is the farm-gate price ratio of $\mathrm{N}$-fertilizer to paddy. Our key interest is examining the effects of different training approaches on $\mathrm{N}$-fertilizer use in both the short and long term; as such, in the empirical estimation, we include:

- experiment under very intensive training in 2003-2005 ( $\left.A 1_{2004}\right)$

- conventional practices for Type A farmers in 2003-2005 (A2 2004

- Type A farmers in $2010\left(A_{2010}\right)$

- experiment under less intensive training in 2003-2005 (B1 2004$)$

- conventional practices for Type B farmers in 2003-2005 (B2 2004$)$

- Type B farmers in 2010 ( $\left.B_{2010}\right)$

- experiment under traditional training in 2003-2005 $\left(C_{2004}\right)$

- Type $C$ farmers in $2010\left(C_{2010}\right)$

The bases for comparison are those farmers who received no training during the period (Type $D$ farmers).

A set of control variables $Z$ includes household demographics (for example, age and educational attainment of the household head, and area of cultivated land) and a region dummy for Guangdong province. ${ }^{3}$ The term $e$ is the idiosyncratic error term. A summary of statistics pertaining to both the dependent and independent variables is presented in Appendix Table A2.

\subsection{Multivariate results}

The model above is estimated by the ordinary least squares method; the results are presented in Table 3. The signs on the province dummy and price ratio are as expected, and consistent with the descriptive statistics (Tables 1 and 3). The estimated coefficient $(-45.90)$ for Fertilizer price/paddy price indicates that the change in prices during 2004 and 2010 increased farmers' N-fertilizer use by $22.6 \mathrm{~kg} / \mathrm{ha},-45.9 \times 0.49$ (1.67-2.16; Table 2$)$, which explains 78 percent of total increase in $\mathrm{N}$-fertilizer $(29=257-228)$. This implies that there are also other factors that have not been considered but have increased $\mathrm{N}$-fertilizer use over the study period.

The most important results are the estimated parameters related to the training approaches. While the estimated results are largely consistent with those presented in Table 1, the magnitudes and statistical significance of different training approaches are empirically identified through multivariate analysis. First, the estimated coefficient (-81.03) of Plot A1 in 2004 is significant and negative, which indicates that the average rate of $\mathrm{N}$-fertilizer use could be reduced

\footnotetext{
3 We also tried to include ratio of migrated labor in household total labor in $\mathrm{N}$ fertilizer use model. We do not report these results for the following three reasons: 1 ) the estimated results for all variables in the model (1) are similar between with and without including the above new variable; 2 ) the ratio of migrated labor in household total labor is likely endogenous but we do not have any good instrument variable; and 3 ) the estimated coefficient for the ratio of migrated labor in household total labor is not statistically significant. Insignificant relationship between $\mathrm{N}$ fertilizer use and off-farm employment could be due to the fact that rice farm size is very small ( 0.26 ha) so that labor availability might not be a major constraint in our study areas.
} 
by $81.03 \mathrm{~kg} /$ ha (Table 3 ), if farmers received intensive training (i.e., guided experiments) in 2004. This represents a reduction of more than 35 percent in $\mathrm{N}$-fertilizer use, as the average rate of $\mathrm{N}$-fertilizer use in the same year was $228 \mathrm{~kg} /$ ha (Table 1 ).

In the short term, less-intensive training is associated with smaller effects on $\mathrm{N}$-fertilizer use reduction. The estimated coefficient for Plot B1 in 2004 is -55.88 (Table 3), and it is statistically significant. However, the magnitude of short-term effects is smaller than that with Plot A1: the reduction was about 26 percent (55.88/228). Although the estimated coefficient is still negative (-21.17) for Type C in 2004, it is not statistically different from that of the control group (Type D farmers). This suggests that traditional training that features the delivery of a one-hour course had little or no impact on reducing farmers' $\mathrm{N}$-fertilizer use in rice production.

Six years after the knowledge training, the effectiveness of reducing $\mathrm{N}$-fertilizer use persisted among the Type A and Type $\mathrm{B}$ farmers, though the magnitude of that impact declined. As shown in Table 3, the coefficient of variable Type A in 2010 is significant and negative; this suggests that, ceteris paribus, the overall rate of $\mathrm{N}$-fertilizer use in 2010 rice production was $47.15 \mathrm{~kg} /$ ha (or 18 percent) lower than the $\mathrm{N}$-fertilizer used by the control group farmers (257 kg/ha) who did not participate in the SSNM knowledge training. The magnitude of effects is smaller than that in the short term (-81.03); this implies an attenuating effect of training in the long term. Similar effects can be observed for less-intensive training. The coefficient of variable Type B in 2010 is significant and negative $(-26.96)$ - a figure that is lower than that seen with respect to the short-term effects (Plot B1 in 2004: -55.88).

\subsection{Discussion}

The results from both the descriptive and multivariate analyses show that knowledge training matters, but that more innovative approaches are needed. Innovative and participatory approaches are essential to improving the efficiency of $\mathrm{N}$-fertilizer use in both the short and long term. The traditional method of offering a onetime, top-down knowledge training course had little impact in the long run. Similar results were also found in other studies. For example, Ma et al. (2014) found that although extension services have stimulated the use of formula fertilizer in Taihu Basin, the use of formula fertilizer had not improved fertilizer use efficiency. That is, short-term training does not have a large impact, but farmers

Table 3

Estimated results of farmers' nitrogen fertilizer use in rice production in Jiangsu and Guangdong, using ordinary least squares regression, 2004-2010.

\begin{tabular}{lc}
\hline & Nitrogen use (kg/ha) \\
\hline Fertilizer price/paddy price & $-45.90^{* *}(2.27)$ \\
Type A farmers & $-81.03^{* * *}(4.11)$ \\
Plot A1 in 2004 & $-28.26(1.43)$ \\
Plot A2 in 2004 & $-47.15^{* *}(2.41)$ \\
A in 2010 & \\
Type B farmers & $-55.88^{* * *}(3.88)$ \\
Plot B1 in 2004 & $-21.20(1.47)$ \\
Plot B2 in 2004 & $-26.96^{*}(1.92)$ \\
B in 2010 & $-21.17(1.21)$ \\
Type C in 2004 & $10.00(0.59)$ \\
Type C in 2010 & $-62.81^{* * *}(8.02)$ \\
Guangdong province (Yes $=1$; No $=0)$ & $0.31(0.84)$ \\
Age of household head (years) & $-2.27^{*}(1.84)$ \\
Education of household head (years) & $28.05(1.35)$ \\
Cultivated land (ha) & $345.43^{* * *}(7.44)$ \\
Intercept & 481 \\
$N$ &
\end{tabular}

Figures in the parentheses are absolute t-ratios of the estimates.

${ }^{*}$, ,** and ${ }^{* * *}$ denote statistical significance at the $10 \%, 5 \%$, and $1 \%$ levels, respectively. Source: Authors' survey.
Table 4

Rice yield for the samples used in this study ( $\mathrm{kg} / \mathrm{ha})$.

\begin{tabular}{|c|c|c|c|c|c|}
\hline & \multicolumn{3}{|l|}{2004} & \multicolumn{2}{|l|}{2010} \\
\hline & Yield & $\begin{array}{l}\text { A1 vs A2 } \\
\text { B1 vs B2 }\end{array}$ & $\mathrm{A} 1 / \mathrm{B} 1 / \mathrm{C}$ vs $\mathrm{D}$ & Yield & $\mathrm{A} / \mathrm{B} / \mathrm{C}$ vs $\mathrm{D}$ \\
\hline Type A farmers & & & & 5844 & $(0.886)$ \\
\hline Plot A1 & 5431 & $(0.660)$ & $(0.152)$ & & \\
\hline Plot A2 & 5274 & & & & \\
\hline Type B farmers & & & & 5421 & $(0.393)$ \\
\hline Plot B1 & 6138 & $(0.398)$ & $(0.389)$ & & \\
\hline Plot B2 & 6000 & & & & \\
\hline Type C & 5972 & & $(0.786)$ & 5654 & $(0.794)$ \\
\hline Type D & 5904 & & & 5770 & \\
\hline
\end{tabular}

The figures in parentheses are absolute p-ratios of estimates.

need to internalize the information, understand what they do and why they do it. This requires more intensive and long-term training.

While N-fertilizer use can be reduced significantly through intensive training programs, there is also concern that continued reductions could have adverse effects on rice yield. The results of this study show that in the study area, reductions in $\mathrm{N}$-fertilizer use had no effect on rice yield in 2004. For example, despite the fact that $\mathrm{N}$-fertilizer use in Plot A1 (198 kg/ha) was $52 \mathrm{~kg}$ (or 26 percent) lower than that on Plot A2 in 2004 (146 kg/ha; Table 1), the average rice yield on Plot A1 (5431 kg) was higher than that on Plot A2 $(5274 \mathrm{~kg}$ ) in the same year (Table 4$)$. A similar story was found for Plot B1 and Plot B2 of the Type B farmers in 2004 (Table 1 for $\mathrm{N}$-fertilizer use, and Table 4 for rice yield). Moreover, there was also no statistical difference in rice yield between Plot A1 (or B1 or C) and Type D farmers' fields (column 3, Table 4).

The results of this study, furthermore, show that the reduction of $\mathrm{N}$-fertilizer use had no effects on rice yield over a longer time period. Despite continued reductions in $\mathrm{N}$-fertilizer use by Type $\mathrm{A}$ and Type B farmers in 2004-2010, the results of statistical tests show that there was no difference in rice yield between Type A (or B) farmers and Type D farmers in 2010 (final column, Table 4). That is, in the sample villages, the continued reduction of $\mathrm{N}$-fertilizer use in rice production did not harm rice yield. ${ }^{4}$

The increased $\mathrm{N}$-fertilizer use efficiency (i.e., reduced usage without reducing crop yield) in rice production through SSNM training is reflected in farmers' improved knowledge of $\mathrm{N}$ management. During the follow-up survey in 2010, we asked several qualitative questions about farmers' knowledge of $\mathrm{N}$ use in rice production. Specifically, we asked each farmer, "If $\mathrm{N}$-fertilizer use were reduced by 10 percent in your rice production, would the rice yield be affected?" The results show that nearly half of the farmers ( 45 percent) stated a definite reduction in rice yield (Table 5). However, as shown above, in this study, a reduction of overall $\mathrm{N}$-fertilizer use by 10 35 percent by various groups of farmers in 2004 and 2010 had no adverse effect on rice yields. This finding confirms our expectation that Chinese farmers are generally lacking knowledge on the efficient use of $\mathrm{N}$ in crop production.

When examining farmers' perceptions of reduced $\mathrm{N}$-fertilizer use and its consequences for rice yield under different training approaches (Table 5), two important points are worth noting. First, SSNM knowledge training does matter. The percentages of Type A, Type B, and Type $C$ farmers who perceived "no effects" on rice yield as a result of a 10-percent reduction in $\mathrm{N}$-fertilizer use reached 64

\footnotetext{
4 On the average, rice yield for farmers A increased but it decreased for farmers B, C and $\mathrm{D}$. The fall of rice yield over time is statistically significantly only for farmers B. One likely explanation for no significant increase in rice yield in 2010 over 2004 might be the fact that China, particularly in Jiangsu and Guangdong (this study area), suffered from severe flood in 2010 (MOA (Ministry of Agriculture), 2011). During our field survey in 2010, some farmers also told us their paddy fields suffered from the severe flood.
} 
Table 5

Farmers' perception of yield loss when reducing nitrogen use by 10 percent in 2010 (\%).

\begin{tabular}{lllc}
\hline & Certainly reduced & No effect & No idea \\
\hline Type A & 23 & 64 & 13 \\
Type B & 44 & 47 & 9 \\
Type C & 42 & 50 & 8 \\
Type D & 71 & 29 & 0 \\
Average & 45 & 47 & 8 \\
\hline
\end{tabular}

The survey question was "If $\mathrm{N}$-fertilizer use were reduced by 10 percent in your rice production, would the rice yield be affected?"

percent, 47 percent, and 50 percent, respectively. These figures were much higher than that for the control-group farmers (Type D farmers: 29 percent). The training effects the farmers attained were based on knowledge acquisition. Second, knowledge gaps on N management persisted, even after intensive field guidance. For example, 23 percent of Type $A$ farmers and $42-44$ percent of Type $B$ and Type $\mathrm{C}$ farmers perceived a definite yield loss stemming from a $10-$ percent reduction in $\mathrm{N}$-fertilizer use in 2010 (Table 5); nonetheless, these figures are much lower than that of the control group farmers (Type D farmers: 71 percent).

Factors other than knowledge training also affected farmers' $\mathrm{N}$-fertilizer use in rice production. For example, changes in the relative prices of fertilizer and rice affected their incentives to use $\mathrm{N}$-fertilizer. Eliminating the current preferential tax on China's domestic fertilizer industry could potentially increase fertilizer prices in the short term; however, given the fact that China's current prices of $\mathrm{N}$-fertilizer and rice are similar to those in the international market, there seems to be no room for price interventions. In addition, Table 3 shows a negative coefficient for Education of the household head, which underscores the importance of knowledge acquisition and capacitybuilding. Finally, the insignificance of the coefficient for Cultivated land may be explained by the fact that farm size in this study area is too small to have an impact. In our sample, average cultivated land was 0.26 ha only, ranged from 0.03 to 1.67 ha. However, several recent studies with relatively larger farm size samples showed that increase in farm size can reduce $\mathrm{N}$-fertilizer use in maize production (Huang et al., 2012; Jia et al., 2013; Zhou et al., 2010).

\section{Conclusions}

Chemical fertilizer, particularly $\mathrm{N}$-fertilizer, plays an important role in increasing food production in China. However, farmers in China use much more $\mathrm{N}$-fertilizer than is needed. The excessive use of $\mathrm{N}$-fertilizer is prevalent and worsening. The findings of this study indicate that knowledge training through the direct engagement of farmers in field experiments is an innovative and effective approach to reducing excessive $\mathrm{N}$ use without adversely affecting crop yield, in both the short and long term. Moreover, the results of this study also indicate that the effectiveness of knowledge training could slowly wane over time, if there are no additional efforts following the initial training.

The findings of this study have important policy implications visà-vis the sustainability of China's agricultural development and the mitigation of climate change. As discussed in the introduction section, excessive fertilizer use has led to severe environmental problems in China, which could in turn greatly undermine agricultural sustainability. Furthermore, because the majority of agricultural GHG emissions relate directly to $\mathrm{N}$-fertilizer use in agricultural production, knowledge training that focuses on improving $\mathrm{N}$ management should be mainstreamed into China's national plan for mitigating and coping with climate change. Reducing $\mathrm{N}$-fertilizer use through knowledge training is a win-win measure that could result in enhanced environmental sustainability, increased farm income, and improved food security.
The results of this study also have implications regarding China's knowledge transfer system and innovation in agriculture. Recently, several experimental studies have shown that through the country's public extension system, knowledge training could significantly reduce farmers' $\mathrm{N}$-fertilizer use in maize and wheat production over the year in which the training course is offered (Huang et al., 2012; Jia et al., 2013). These studies, however, provide evidence only of short-term effects. The generalizability of such training and its long-term effects should be scrutinized. The results of the current study suggest that to have a persistent, long-term effect, more intensive training through farmers' own field trials and/or onsite demonstrations should be offered through the public extension program. This calls for innovation to extension approaches that encourages bottom-up participation. Indeed, the old saying of "seeing is believing" seems appropriate for describing knowledge training in agricultural technology.

\section{Acknowledgements}

The authors acknowledge the financial supports of the Ministry of Science and Technology of the People's Republic of China (2012CB955700), the National Natural Science Foundation of China (71333013 and 71303228), the China-UK Sustainable Agriculture Innovation Network, and the Sino-German Research Project of the Ministry of Science and Technology (2007DFA30850).

\section{Appendix}

Table A1 Samples of households and plots in sample villages in 2004 and 2010.

\begin{tabular}{lcc}
\hline & 2004 & 2010 \\
\hline Sample of households in 2004 & 244 & - \\
Sample of households used in this study & 180 & 180 \\
Type A farmers* & 25 & 22 \\
Plot A1 & 25 & - \\
Plot A2 & 25 & - \\
Type B farmers* & 124 & 99 \\
Plot B1 & 124 & - \\
Plot B2 & 124 & 38 \\
Type C & 54 & 21 \\
Type D & 41 & - \\
\hline
\end{tabular}

* Type A and Type B farmers each had two subplots in 2004. In 2010, the largest plot of rice production for each farmer type was selected, and the number of households equals the number of plots.

Table A2 Descriptive statistics of major variables.

\begin{tabular}{|c|c|c|c|c|c|}
\hline Variable & Sample & Mean & Std. dev. & Min & Max \\
\hline Nitrogen fertilizer (kg/ha) & 481 & 197.0 & 85.8 & 12.8 & 607.5 \\
\hline $\begin{array}{l}\text { Price ratio (N-fertilizer/ } \\
\text { paddy) }\end{array}$ & 481 & 2.01 & 0.29 & 1.50 & 2.51 \\
\hline \multicolumn{6}{|l|}{ Type A farmers } \\
\hline Plot A1 in 2004 & 481 & 0.046 & 0.21 & 0 & 1 \\
\hline Plot A2 in 2004 & 481 & 0.046 & 0.21 & 0 & 1 \\
\hline$A$ in 2010 & 481 & 0.046 & 0.21 & 0 & 1 \\
\hline \multicolumn{6}{|l|}{ Type B farmers } \\
\hline Plot B1 in 2004 & 481 & 0.206 & 0.40 & 0 & 1 \\
\hline Plot B2 in 2004 & 481 & 0.206 & 0.40 & 0 & 1 \\
\hline B in 2010 & 481 & 0.206 & 0.40 & 0 & 1 \\
\hline Type C in 2004 & 481 & 0.079 & 0.27 & 0 & 1 \\
\hline Type C in 2010 & 481 & 0.079 & 0.27 & 0 & 1 \\
\hline Type D in 2004 & 481 & 0.043 & 0.20 & 0 & 1 \\
\hline Type D in 2010 & 481 & 0.043 & 0.20 & 0 & 1 \\
\hline $\begin{array}{l}\text { Guangdong province } \\
\quad(Y e s=1 ; \mathrm{No}=0)\end{array}$ & 481 & 0.56 & 0.50 & 0 & 1 \\
\hline $\begin{array}{l}\text { Age of household head } \\
\text { (years) }\end{array}$ & 481 & 53.0 & 10.2 & 26 & 79 \\
\hline $\begin{array}{l}\text { Education of household head } \\
\text { (years) }\end{array}$ & 481 & 6.73 & 2.86 & 0 & 15 \\
\hline Cultivated land (ha) & 481 & 0.26 & 0.16 & 0.03 & 1.67 \\
\hline
\end{tabular}




\section{References}

Buresh, R.J., 2009. The SSNM concept and its implementation in rice. Kota Kinabalu, Malaysia, 8-10 December 2009.

Byerlee, D., de Polanco, E.H., 1986. Farmers' stepwise adoption of technological packages: evidence from the Mexican Altiplano. Am. J. Agric. Econ. 68 (3), 519-528.

Cai, G.X., Chen, D.L., Ding, H., Pacholski, A., Fan, X.H., Zhu, Z.L., 2002. Nitrogen losses from fertilizers applied to maize, wheat and rice in the North China Plain. Nutr. Cycl. Agroecosys. 63 (2-3), 187-195.

Chen, Q., Zhang, X., Zhang, H., Christie, P., Li, X., Horlacher, D., et al., 2004. Evaluation of current fertilizer practice and soil fertility in vegetable production in the Beijing region. Nutr. Cycl. Agroecosys. 69 (1), 51-58.

Chen, X., Zhang, F., Römheld, V., Horlacher, D., Schulz, R., Böning-Zilkens, M., et al., 2006. Synchronizing $\mathrm{N}$ supply from soil and fertilizer and $\mathrm{N}$ demand of winter wheat by an improved Nmin method. Nutr. Cycl. Agroecosys. 74 (2), 91-98.

Cui, Z., Chen, X., Miao, Y., Zhang, F., Sun, Q., Schroder, J., et al., 2008. On-farm evaluation of the improved soil nmin-based nitrogen management for summer maize in North China Plain. Agron. J. 100 (3), 517-525.

Fan, M., Lu, S., Jiang, R., Liu, X., Zeng, X., Goulding, K., et al., 2007. Nitrogen input, $\mathrm{N}-15$ balance and mineral $\mathrm{N}$ dynamics in a rice-wheat rotation in southwest China. Nutr. Cycl. Agroecosys. 79 (3), 255-265.

Guo, J.H., Liu, X.J., Zhang, Y., Shen, J.L., Han, W.X., Zhang, W.F., et al., 2010. Significant acidification in major Chinese croplands. Science 327 (5968), 1008-1010.

He, F., Jiang, R., Chen, Q., Zhang, F., Su, F., 2009. Nitrous oxide emissions from an intensively managed greenhouse vegetable cropping system in Northern China. Environ. Pollut. 157, 1666-1672.

Heffer, P., 2009. Assessment of Fertilizer Use by Crop at the Global Level. International Fertilizer Industry Association (IFA), Paris, France.

Heisey, P.W., Norton, G.W., 2007. Fertilizers and other farm chemicals. In: Evenson, R., Pingali, P. (Eds.), Handbook of Agricultural Economics, vol. 3. Elsevier B.V, Amsterdam, The Netherlands.

Hu, R., Cao, J., Huang, J., Peng, S., Huang, J., Zhong, X., et al., 2007. Farmer participatory testing of standard and modified site-specific nitrogen management for irrigated rice in China. Agric. Syst. 94 (2), 331-340.

Hu, R., Yang, Z., Kelly, P., Huang, J., 2009. Agricultural extension system reform and agent time allocation in China. China Econ. Rev. 20 (2), 303-315.

Huang, J., Hu, R., Cao, J., Rozelle, S., 2008. Training programs and in-the-field guidance to reduce China's overuse of fertilizer without hurting profitability. J. Soil Water Conserv. 63 (5), 165-167.

Huang, J., Wang, X., Zhi, H., Huang, Z., Rozelle, S., 2011. Subsidies and distortions in China's agriculture: evidence from producer - level data. Aust. J. Agric. Resour. Econ. 55, 53-71.
Huang, J., Xiang, C., Jia, X., Hu, R., 2012. Impacts of training on farmers' nitrogen use in maize production in Shandong, China. J. Soil Water Conserv. 67 (4), 321-327. doi:10.2489/jswc.67.4.321.

IRRI, 2012. Site-Specific Nutrient Management. International Rice Research Institute. $<$ http://www.knowledgebank.irri.org/rkb/ssnm> (accessed 06.12.).

Jia, X., Huang, J., Xiang, C., Hou, L., Zhang, F., Chen, X., et al., 2013. Farmer's adoption of improved nitrogen management strategies in maize production in China: an experimental knowledge training. J. Integr. Agric. 12 (2), 364-373.

Khanna, M., 2001. Sequential adoption of site-specific technologies and its implications for nitrogen productivity: a double selectivity model. Am. J. Agric. Econ. 83 (1), 35-51.

Ma, L., Feng S., Reidsma, P., Qu, F. Heerink, N., 2014. Identifying entry points to improve fertilizer use efficiency in Taihu Basin, China. Land Use Policy 37, 52-59.

Ma, W., Li, J., Ma, L., Wang, F., Sisák, I., Cushman, G., et al., 2008. Nitrogen flow and use efficiency in production and utilization of wheat, rice, and maize in China. Agric. Syst. 99 (1), 53-63.

MOA (Ministry of Agriculture), 2011. China Agricultural Yearbook. China Agricultural Press, Beijing.

Peng, S., Huang, J., Zhong, X., Yang, J., Wang, G., Zou, Y., et al., 2002. Challenge and opportunity in improving fertilizer-nitrogen use efficiency of irrigated rice in China. Agric. Sci. China 1 (7), 776-785.

Peng, S., Buresh, R., Huang, J., Yang, J., Zou, Y., Zhong, X., et al., 2006. Strategies for overcoming low agronomic nitrogen use efficiency in irrigated rice systems in China. Field Crops Res. 96, 37-47.

SAIN, 2010. China-UK sustainable agriculture innovation network: policy brief 1 . $<$ http://www.sainonline.org/English.html>.

Wang, G., Dobermann, A., Witt, C., Sun, Q., Fu, R., 2001. Performance of site-specific nutrient management for irrigated rice in Southeast China. Agron. J. 93, 869-878.

Xiang, C., 2012. The impacts of training and extension incentive on farmer's fertilizer use: a case study on the extension of nitrogen management technology in maize and wheat (in Chinese, Unpublished doctoral thesis). Center for Chinese Agricultural Policy, Chinese Academy of Sciences.

Yan, Y., Tian, J., Fan, M., Zhang, F., Li, X., Christie, P., et al., 2012. Soil organic carbon and total nitrogen in intensively managed arable soils. Agric. Ecosyst. Environ. 150, 102-110.

Zhou, Y., Yang, H., Mosler, H., Abbaspour, K., 2010. Factors affecting farmers' decisions on fertilizer use: a case study for the Chaobai watershed in Northern China. J. Sust. Dev. 4, 80-102.

Zhu, Z.L., Chen, D.L., 2002. N-fertilizer use in China - contributions to food production, impacts on the environment and best management strategies. Nutr. Cycl. Agroecosys. 63 (2-3), 117-127. 